\title{
Borderline QTCB
}

National Cancer Institute

\section{Source}

National Cancer Institute. Borderline QT CB. NCI Thesaurus. Code C92228.

An electrocardiog raphic finding in which the QT interval corrected for heart rate using Bazett's formula is slightly prolonged. Thresholds for different age, gender, and patient populations exist. (CDISC) 